\title{
HISTORIAS EN TRÁNSITO
}

\section{Luis Urquieta Robles}

Univ Politècnica de València, Màster Universitari en Arts Visuals i Multimèdia

\begin{abstract}
Resumen
"Historias en tránsito" es un proyecto interactivo sonoro que se plantea como una metáfora, una representación del proceso inmigratorio que han vivido miles de personas, generada a partir de la abstracción de un espacio de circulación en un aeropuerto. Esta puesta en escena es confrontada y entrelazada con la realidad del relato oral de un grupo de inmigrantes residentes en Barcelona. Por medio de esta propuesta interactiva, se busca evidenciar una situación social que en nuestros días sigue aconteciendo pero no se valoriza de manera total, por lo que el proyecto pretende presentar esa cara menos visible. Si bien el trabajo está vinculado a una instalación interactiva, sus bases se enfocan en la antropología visual, utilizando como metodología matriz las entrevistas de tipo semiestructuradas y de foto elicitación a diversos inmigrantes, con el fin de abordar la carga de memoria de cada uno de ellos asociada a un grupo de imágenes presentadas que guardan relación con su territorio y cultura.
\end{abstract}

\section{Palabras-clave: INMIGRACION; ANTROPOLOGÍA VISUAL; HISTORIA} ORAL; INSTALACION; ARTE SONORO

\section{HISTORIES IN TRANSIT}

\begin{abstract}
"Story in transit" is an interactive sound project stated as a metaphor, a representation of the migratory process that thousands of people have experienced, generated as an abstraction of the transit space inside the airport. This mise-en-scène is confronted and interlaced with the reality of the oral statements of a group of immigrants currently residing in Barcelona. Through this interactive approach, it is sought to represent a social situation which continues to happen even today, but isn't considered in its whole. This project attempts to present the less visible face of the issue. Though the work is presented as an interactive installation, its conceptual foundation lies in visual anthropology; using semi-structured interviews and photo-elicitation applied to a group of diverse immigrants as fundamental methodology, in order to approach the load of memory of each immigrant in relation to a selection of images associated to their original territory and culture.
\end{abstract}

\section{Keywords: INMIGRATION; VISUAL ANTROPOLOGY; ORAL HISTORY; INSTALLATION; SOUND ART}

\footnotetext{
Urquieta Robles, Luis. 2016. "Historias en tránsito". AusArt 4(2): 113-126 DOI: 10.1387 /ausart.17107
}

\section{AUSART}




\section{INTRODUCCIÓN}

El fenómeno migratorio se entiende como el desplazamiento de personas a un país o región al cual no pertenecen. Desde que el hombre es hombre siempre ha buscado la forma de desarrollar su vida en aquellos lugares que mejor le acomoden geográficamente, debiendo desplazarse miles de kilómetros para encontrar un lugar ideal, un lugar que le proporcione una mejor calidad de vida. "Lo que en un origen eran desplazamientos diarios para proveerse de alimentos, se fue alargando porque el territorio más cercano se había empobrecido y ya no podía satisfacer las necesidades de supervivencia de los grupos. La migración, como forma eficaz de búsqueda de nuevos recurso, se ha extendido a lo largo de los siglos" (Mas 2001, 9) para así comenzar la génesis del asentamiento.

Durante el inicio del presente siglo, España vivió una inusitada corriente migratoria, en donde "Cataluña, Madrid y Comunidad Valenciana se concentró casi el 58\% de toda la población extranjera empadronada en España" (Aja \& Arango 2006, 308), siendo Cataluña la primera comunidad con el número más alto de extranjeros hacia el año 2005 (un 21,6\%) por encima de Madrid con un $20,8 \%$ y Valencia con un $15,5 \%$.

El tema de la inmigración en Europa se ha insertado fuertemente en los noticiarios españoles durante el último tiempo; lamentablemente, no por entregar noticias esperanzadoras. Hemos sido testigos de las innumerables pateras colmadas de personas que no logran llegar a tierras europeas; el éxodo de ciudadanos sirios que han debido abandonar su país a causa de la guerra. El crecimiento en gran parte de Europa de grupos de extrema derecha que tachan a la inmigración como la gran culpable de las crisis sucedidas en sus respectivos países. Sin ir más lejos en el tiempo, uno de los detonantes del triunfo del Brexit, fue el recelo que la población tiene ante los inmigrantes. Este temor fue lo que generó, en gran medida, la partida del Reino Unido de la Unión Europea. Los medios nos muestran una dura realidad, toda expresada en números y porcentajes, pero más allá de las cifras que inundan los noticiaros en torno al tema, son vidas que llevan consigo una carga tremendamente potente y que poco sabemos de esas experiencias individuales.

Para ello, haremos uso de la historia oral, que si bien es considerada como "la más nueva y la más antigua forma de hacer historia" ya que los antiguos griegos la usaban ante la escases de fuentes escritas; no fue hasta 1948 cuando nació como campo de estudio a través de Allan Nevins, quien fundó la 
Oral History Research Office en la Universidad de Columbia, Estados Unidos (Meyer \& Olivera 1971).

Desde su inserción como campo de estudio, ha debido abrirse camino ante las críticas por ser considerado un método subjetivo, siendo esto, a mi entender, un punto a favor por tratarse de documentos que pueden ayudar a complementar una información o hecho histórico que si haya sido registrado a la manera tradicional. Fue gracias a los cambios sociales, intelectuales y técnicos que la historia oral pudo ser revalorada y tomada en cuenta dentro del quehacer de las ciencias sociales.

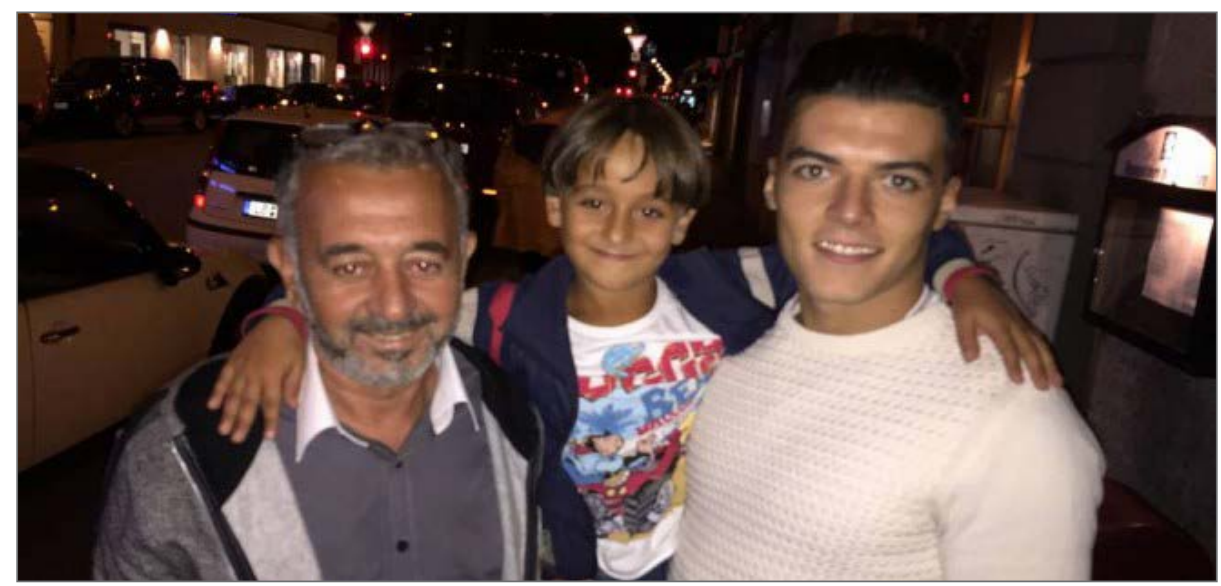

Fig. 1. Osama Abdul Mohsen (a la izquierda) en Madrid junto a dos de sus cuatro hijos. Abdul Mohsen se hizo conocido mundialmente al ser fotografiado justo en el instante en que una periodista le hace una zancadilla mientras el con su hijo menor trataban de cruzar la frontera de Hungría. 2015.

Historias en tránsito se traza como una reflexión reivindicativa, de visualización y una representación del esfuerzo y las vivencias que han sobrellevado miles de personas que se han transformado en inmigrantes para conseguir y entregar a sus familias una mejor calidad de vida, dado que en sus países de origen la situación política, social o económica se habría vuelto insostenible.

Ante este fenómeno, es importante generar un discurso respecto a dichas experiencias migratorias. De allí que he formulado un proyecto en un grupo en concreto conformado por 10 entrevistados residentes en Barcelona y a partir de sus historias y por medio de la utilización de nuevas tecnologías se pretende insertar en el tejido urbano de la ciudad; problemáticas que continúan vigentes y que son necesarias mantenerlas en la palestra. 


\section{METODOLOGÍA DE TRABAJO}

Las tecnologías blandas posibilitan transformar las relaciones entre las personas por medio de diversos métodos de trabajo, haciendo de puente entre la técnica aplicada, o tecnología dura, y los distintos entes que componen el tejido social para que de esta manera se genere critica y se puedan modificar las formas existentes de relacionarnos. En este sentido historias en tránsito pretende abordar el tema inmigratorio desde su componente más humano, hacerlo visible y poder plantar discusión en torno a las políticas que los diversos estados están implementando para afrontar esta realidad.

La historia oral es un método para la recuperación de los testimonios de sujetos que protagonizaron un hecho histórico, a través de la entrevista. Se trata sin duda de una técnica específica de investigación contemporánea al servicio de varias disciplinas. Utilizada en el terreno de la historia, las fuentes que se producen a través de las entrevistas resultan fundamentales para la comprensión de los fenómenos contemporáneos (Schwarzstein 1998). Se trabaja de manera directa con aquellas personas que fueron protagonistas o testigos de un hecho en concreto, por lo que su alcance es hasta hechos contemporáneos, limitando de esta manera su rango de estudio, pero que sin dudas, nos permite recuperar una parte de nuestra historia más reciente, a través de los testimonios, como uno de los elementos conformadores de memoria (Delgado 2006).

Esta nueva, y vieja, forma de hacer historia aproxima visiones de esferas mucho más diversificadas que las que trata la historia más tradicional, actores que no son tenidos en cuenta como grupos marginales u opositores a los sectores que tradicionalmente detentan el poder (Mariezkurrena 2008), como obreros, mujeres, niños, pueblos originarios, inmigrantes... y así poder reconstruir desde fuentes no tradicionales.

Para poder llevar a cabo este proyecto es fundamental contar con un número de entrevistados que estén dispuestos a colaborar con esta labor. Las ONGs y asociaciones vinculadas con la problemática inmigratoria son trascendentales para lograr llevar este mensaje y generar una mayor convocatoria. La importancia de este llamamiento es poder tener un grupo de personas interesadas en el proyecto, ya que el objetivo dentro del campo de la historia oral y la metodología aplicada, es entender una vivencia y no obtener meros datos 
abstractos. El éxito de cada entrevista depende en gran medida de la capacidad de empatía que existiese entre entrevistador y entrevistado, para lo cual era importante hacer un proceso previo de contacto por medio de correos electrónicos o llamados telefónicos. Luego, y antes de comenzar con la grabación de las entrevistas, se presenta de forma clara la intención del proyecto al entrevistado, junto a una descripción de las motivaciones artísticas que lo han configurado y los proyectos anteriores realizados para generar un ambiente comunicativo favorable; les reiteraba de qué trataba el proyecto, cuál era mi procedencia, mi ocupación y mis motivaciones para trabajar este tema, para que de algún modo existiera más confianza entre ambas partes, el entrevistado se sintiese cómodo y así obtener mejores resultados. La involucración por parte del entrevistado es esencial, para ello también, es determinante el poder entregar confianza al participante, proporcionando condiciones básicas para una correcta sesión de trabajo junto a él. Dentro de éstas condiciones para el optimo desarrollo del trabajo investigativo es necesario contar con un entorno propicio para el desarrollo del trabajo, preferentemente su hogar; usar solamente luz indirecta para generar una sensación de naturalidad al momento de la realización de la entrevista; de igual manera, procurar mantener lo más discretamente ubicados el micrófono y cámara de video. Debe realizarse una investigación previa respecto a la situación del país de origen del entrevistado, su cultura y hechos importantes para la historia de su nación, para que de esta manera se pueda realizar una entrevista fluida.

Esta entrevista constaba de un cuestionario de 24 preguntas que buscaban ahondar tanto en el pasado previo al momento de dejar su país de origen como en sus metas y proyectos. Al momento de realizar la entrevista, es vital poner suma atención no sólo en los que el entrevistado dice, sino también en como lo dice. Su expresión facial, entonación, gestos, el movimiento de sus manos y silencios nos aportan mucho respecto a la intención que le da al momento de contar su historia o lo significativo que puede ser para el dicho instante. Cada uno de estos pequeños detalles aporta una valiosa información.

Las preguntas del cuestionario tienen como objetivo indagar en sus experiencias de vida desde que decidieron realizar el viaje a España hasta que lograron asentarse en la ciudad de Barcelona. Al conocer dicho proceso, es posible ahondar en cuestiones en detalles humanos que abren paso a problemáticas sociales específicas en las que resultase interesante profundizar, para posteriormente incorporarlas como eje principal de sus historia de vida. 


\section{Cuestionario}

1.- Motivos por los que emigró

2.- Tiempo que lleva residiendo aqui

3.- Vino solo o acompañado

4.- Que recuerda de la despedida

5.- Fue a por los suyos

6.- Cuales fueron las mayores dificultades al venir a España

7.- Sintió desprotección las primeras semanas de llegado a España

8.- Fue recibido por alguien

9.- Que sucedia social y politicamente en su pais de origen

10. - Ha podido regresar a su pais

11.- Nota cambios importante en lo politico y social

12. - Siente que ganó/perdió algo al momento de emigrar
13.- Por qué Barcelona

14.- Cuales eran tus metas al emigrar

15.- Que lo motiva a construir su vida aqui

16.- Crees que las has conseguido

17.- Sientes que la comunidad catalana los ha acogido positivamente

18.- En que aspectos y/o actitudes los ha percibido

19.- Siente apoyo por parte de las autoridades catalanas en la inserción en la sociedad

20.- Desea volver

21.- Tiene fotos de sus familiares

22. - Cual es la relación con éstas fotografias

23.- Que tan a menudo se contacta con sus familiares

24.- Agregarias otra pregunta al cuestionario

Fig. 2. Modelo de preguntas realizadas a entrevistados

Pese a que no existe una estructura que le dé continuidad histórica al relato, es interesante mover las preguntas hacia el pasado o hacia un posible futuro. La primera pregunta, motivos por los cuales emigró, me parece trascendental porque es la génesis de toda las demás preguntas, es en donde se puede extraer una historia potente. Para ello es imprescindible dar la libertad a los entrevistados de responder y explayarse cuanto quieran, aun si se alejan de la pregunta y toma otra dirección.

Este tipo de experiencia ha sido utilizada en variados estudios, esta propuesta se basa en el archivo de historia visual de la Fundación SHOAH, que consistió en entrevistas a los sobrevivientes del Holocausto o a testigos de lo sucedido que actualmente se encuentran distribuidos por todo el planeta. Haciendo hincapié en este colectivo y sirviéndose de un meticuloso y detallado método, el proyecto de la Fundación SHOAH (2015), fue capaz de realizar más de 50.000 entrevistas entre los años 1994 y 1999 en más de 60 países.

La utilización de la memoria como recurso discursivo de un hecho que fue vivido por un grupo considerablemente grande de personas. Mientras que "la historia para él es la historia objetiva, universal, de hechos incontrovertibles (...) la memoria, por el contrario, es historia vivida y seleccionada desde el presente, espontanea y particular. Por lo tanto hay una historia, pero memorias colectivas hay tantas como grupos sociales" (Baer 2005, 24). De este modo la memoria tiene algo de lo que la historia está desprovista, ya que está vincu- 
lada directamente al relato personal de quien vivió o experimentó el suceso, incorporando también sus sensaciones y modos de percibirlas.

La manera en que la fundación trabajó fue por medio de la compilación de historias orales, para de esa manera ir creando un archivo detallado con los recuerdos de todas estas personas involucradas. La historia oral, señala Baer (51), "se refiere a un técnica especifica de investigación contemporánea, basada en entrevistas con participantes e implicados en procesos sociales, registradas en soportes de audio o audiovisuales. En otras palabras, la historia oral es la elaboración/recuperación de historias de vida (en alguna de sus múltiples modalidades) empleada por los historiadores como metodología de reconstrucción de acciones pasadas" que servirán como registro para futuras generaciones.

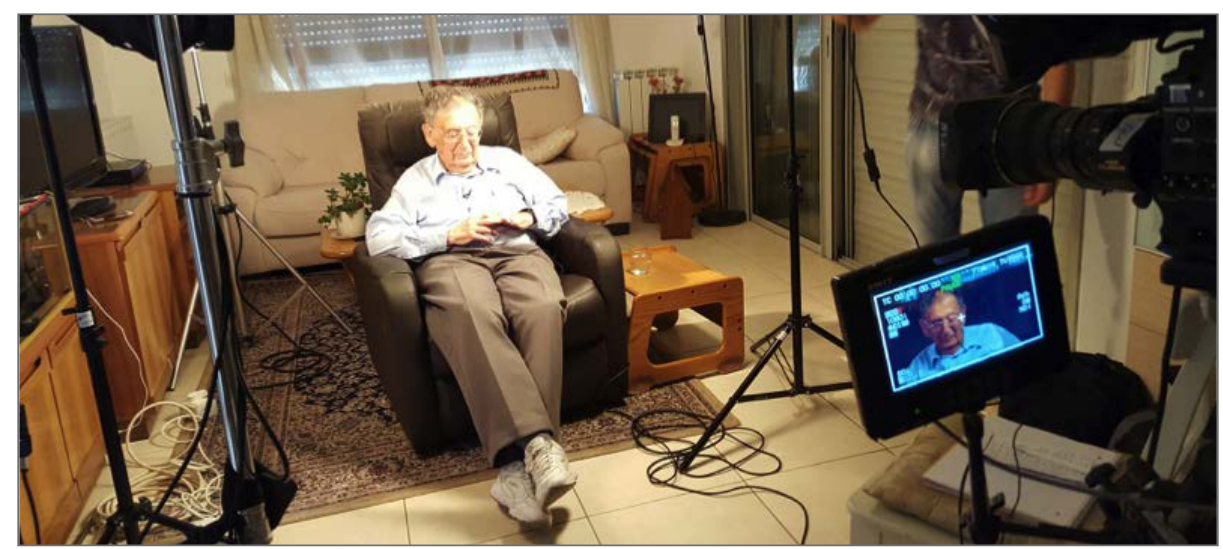

Fig. 3. Registro tras cámaras de entrevista a un sobreviviente del Holocausto. Archivo SHOAH.

El registro del testimonio oral gracias al uso de la cámara de video, permite capturar la imagen y sonido de la entrevista sin perder los elementos fundamentales que proporcionan una visión o perspectiva más integral del entrevistado y su situación al contener, más allá de la (narración/información) verbal aportada, su actitud comunicativa, los silencios o pausas en su mensaje, los gestos que evidencian emociones o sutilezas en sus acciones corporales relacionadas a su testimonio. Además, es posible conseguir un registro que refleja el entorno doméstico en el cual se desarrolla la entrevista y que identifica a la persona en su cotidianidad (Bermúdez \& Rodríguez 2009). 
Utilizando este método puedo ir cualificando variables habituales en los distintos registros de migración, tales como la nacionalidad, el sexo, la edad y un largo etcétera que suelen ser expresadas en números y porcentajes, e incorporando otras, como los motivos de inmigración o las condiciones de trabajo en las que los inmigrantes se ven envueltos, que escapan a las herramientas estadísticas. En este sentido, la historia oral dota a mi investigación de mayor peso al trabajar con autobiografías, entregando información única y personal nacida desde los recuerdos y las sensaciones. Gracias a ella es posible obtener datos que no se podrán encontrar en ningún registro otorgado por oficinas de inmigración o por órganos de gobierno, tanto de los países de donde emigran las personas, como de los estados que acogen a estas personas.

Una vez terminadas las preguntas a los entrevistados, continua la etapa denominada foto elicitación. La foto elicitación, señala Douglas Harper $(2002,13)$, "se basa en la simple idea de la inserción de una fotografía en una entrevista de investigación. La diferencia entre las entrevistas a partir de imágenes y texto, y entrevistas utilizando las palabras solas radica en la forma en que respondemos a estas dos formas de representación simbólica. Esto tiene una base física: las partes del cerebro que procesan la información visual son evolutivamente mayores que las partes que procesan la información verbal. Así, las imágenes evocan elementos más profundos de la conciencia humana de lo que lo hacen las palabras". En definitiva, este método tiene la ventaja de extraer información que se encuentra en la memoria del entrevistado de manera más subjetiva, ya que se trata de la interpretación de la imagen a partir de la biografía de quien está mirando la fotografía, haciéndola única y absolutamente personal.

La foto elicitación surgió en 1957 a manos de John Collier, "un miembro del equipo de investigación multidisciplinar de la Universidad de Cornell" involucrado en un proyecto respecto a las condiciones de salud mental de las comunidades marítimas de Canadá. Collier propuso este sistema de foto elicitación "para examinar cómo las familias se adaptaban a la residencia de personas étnicamente diferentes y a las nuevas formas de trabajo en las fábricas urbanas. La cuestión principal era la base ambiental de estrés psicológico. Los investigadores habían encontrado estos temas difíciles de explorar en las encuestas o entrevistas en profundidad y decidimos probar una nueva técnica de entrevista utilizando imágenes fotográficas de los mundos viejos y nuevos habitadas por los sujetos" (Harper 2002, 14). Esto tuvo como consecuencia encontrar información que otros métodos de consulta, como las encuestas o entrevistas al uso, no fueron capaces de proporcionar. 
Ese fue justamente el motivo por el que decidí incorporar en la entrevista una segunda parte que contemplara la foto elicitación, para de esa manera poder obtener algún tipo de información adicional respecto a recuerdos e historias de las que los entrevistados no mencionaran en la primera etapa correspondiente a las entrevistas. Para ello compilaré una serie de imágenes para cada uno de los países participantes del proyecto. Mi intención con esto, era generar en cada grupo un reconocimiento de las imágenes y provocar algún tipo de emoción, agradable o desagradable, lo que Barthes ([1980]1990, 66) definiría como studium, que en ningún caso les sea indiferente. Dichas imágenes serán en total 10 para cada país y correspondían a tópicos propios de cada nación, involucrando temas como la bandera, el folklore, hitos urbanos de la capital de su país, su actual presidente, protestas y reivindicaciones sociales, personajes históricos, pobreza, represión policial y familia.

La intención de reunir esta serie de imágenes es para poder entablar una relación común entre todos los entrevistados de un país en particular y extraer mediante estos tópicos las distintas miradas genéricas que tienen los ciudadanos de los 10 conceptos ya mencionados. Se establecerán estas fotografías en contextos "espacio/temporales" (Sanz 2008, 249), emplazando personajes del pasado y presente de cada país no en orden cronológico sino de manera aleatoria para que su produjeran saltos de tiempo en cada relato del entrevistado, tornando cada imagen una historia independiente de la otra.

Las entrevistas serán fundamentales para poder conocer el pasado y presente de cada uno de ellos; mientras que el trabajar con imágenes para obtener registros orales permitirá transitar por una brecha que avanzaba en paralelo entre ambos lenguajes. Las imágenes y las palabras han coexistido desde siempre, aparecieron casi al mismo tiempo en la historia de la humanidad, pero se mueven en mundos distintos, carriles paralelos que mantienen intrincadas relaciones.

\section{LA VOZ COMO RECURSO CREATIVO}

La voz y la imagen han estado entrelazadas desde los albores de la humanidad, caminando por "vías paralelas" y coexistiendo cada una con una esencia única. Se dice, eso sí, que antes que la representación en muros de cavernas y muchísimo antes de la escritura, "se produjo algo que quizás es lo que dis- 
tingue de modo fundamental al hombre del animal: la reproducción intencional de un ritmo (...), la escucha deja de ser pura vigilancia y se convierte en creación" (Barthes [1982] 1995, 246). Pese a estar presente con anterioridad a la imagen, tanto el sentido del oído como el acto de escuchar han estado relegados a un segundo plano, dominado por la hegemonía de lo visual, porque dentro de la historia del pensamiento de Occidente la vista es el sentido por excelencia. Pese a esta supremacía de lo visual, se podría afirmar que el sonido es mucho más complejo y completo que la vista al momento de percibir. "El sonido -señala a este respecto David Toop (2007, 61) - es un componente significativo del mapa mental: funciona como unión entre la memoria y las delicadas superposiciones de la percepción, los recuerdos y una sensación, predictiva, de donde, y cómo, y durante cuánto tiempo. Por otra parte, los límites del sonido no son claros, expandiéndose en el aire como lo hacen o llegando desde lugares ocultos, y su significado potencial es vago, más cercano al perfume $o$ al humo que a la solidez de tocar a otra persona, entender una conversación o comer". Tal característica, la de evocar sutilmente por medio de las vibraciones que llegan a nuestros oídos, transforma el sonido en un potente sistema de creación de interrelaciones entre lo presente y lo pasado, incluso llegando tan profundamente en nuestra consciencia como para hacer aflorar sensaciones que se encuentran muy en el interior de nuestra psique.

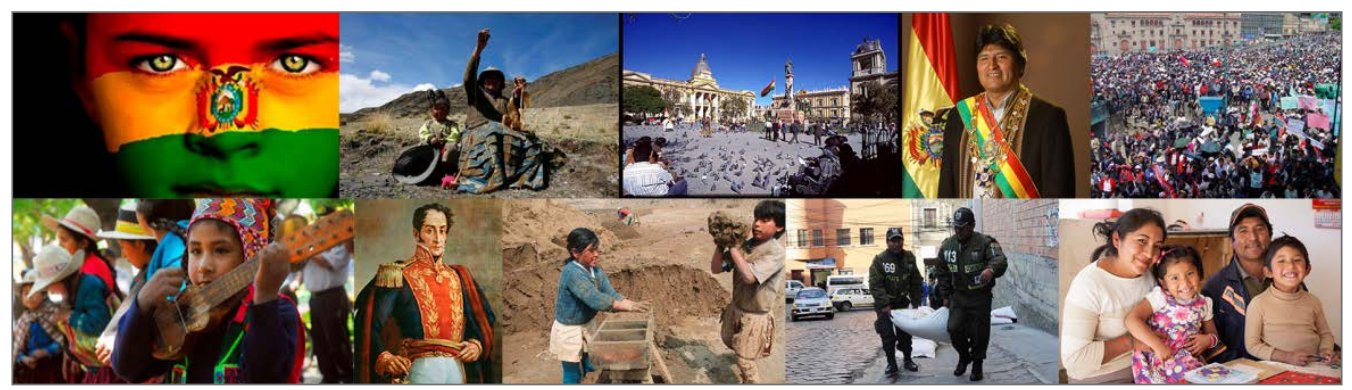

Fig. 4. Ejemplo de montaje con 10 fotografías de foto elicitación hechas para los entrevistados (en este caso, miembros del colectivo boliviano). Éstas hacían referencia a su bandera y su carga emotiva, su cultura, sus tradiciones, hitos urbanos, el poder ejecutivo, movimientos sociales, folklore, héroes patrios, desigualdad, represión y familia.

\section{DESCRIPCIÓN DEL PROYECTO}

La propuesta instalativa está dividida en tres piezas ubicadas a lo largo de la sala, utilizando la totalidad del espacio. Al ingresar a la sala y en el primer tercio de ella se encontrará (inicialmente) la primera obra; se trata de una escultura interactiva construida en base a maletas de diversos colores que en 
su conjunto generan un volumen que puede ser modificado a su antojo por el usuario.

Este volumen es una representación del conjunto de países que constituyen nuestro planeta y a medida que se va modificando dicho volumen, las maletas se van desplazando a través de la sala para luego asentarse en un lugar distinto del original, tal como sucede con la inmigración. Por otra parte, la maleta es por antonomasia el símbolo del viaje. Es lo que uno lleva desde su hogar a otra latitud; corresponde a la metáfora de los recuerdos

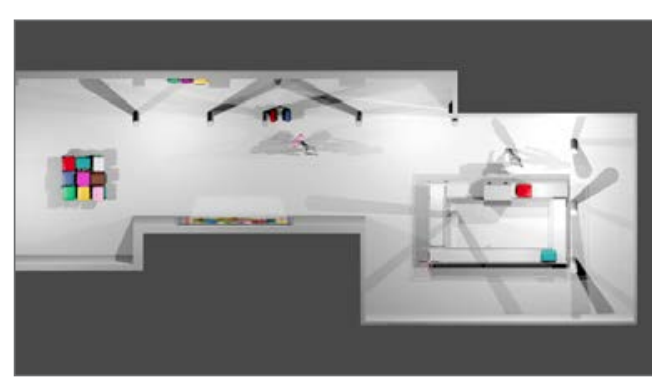

Fig. 5. Maqueta tentativa de la instalación y cada una de las piezas del proyecto. que acompañan al inmigrante que va en busca de nuevas oportunidades.

La segunda pieza es un video (bucle) en plano general que da cuenta de una fila de personas que va avanzando con sus equipajes. Se creará este video con las siluetas en alto contraste de los inmigrantes entrevistados, por lo que no se podrá identificar su color de piel o el tipo de etnia a la que pertenecen. Esta obra hace de transición entre la primera y la tercera ya que representa el acto del

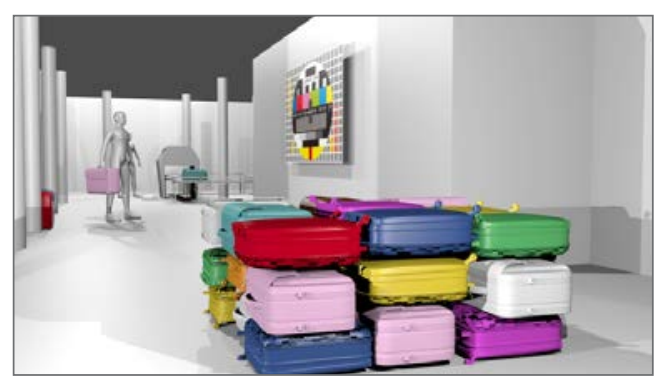

Fig. 6. Detalle del proyecto. traslado, invitando al usuario a cruzar para trasladar la(s) maletas hacia la última pieza.

La pieza tres es un conjunto de cuatro cintas transportadoras que unidas realizan un circuito en forma rectangular. Es ahí donde las maletas de la primera pieza pueden ser llevadas para que estas avancen y entren a un cubículo cerrado que reconocerá cada maleta, y este al identificarla, emitirá el relato de uno de los entrevistados. El resultado de dicho trabajo busca posicionar al usuario por un instante en el lugar del inmigrante y de esa manera visibilizar esta situación. 


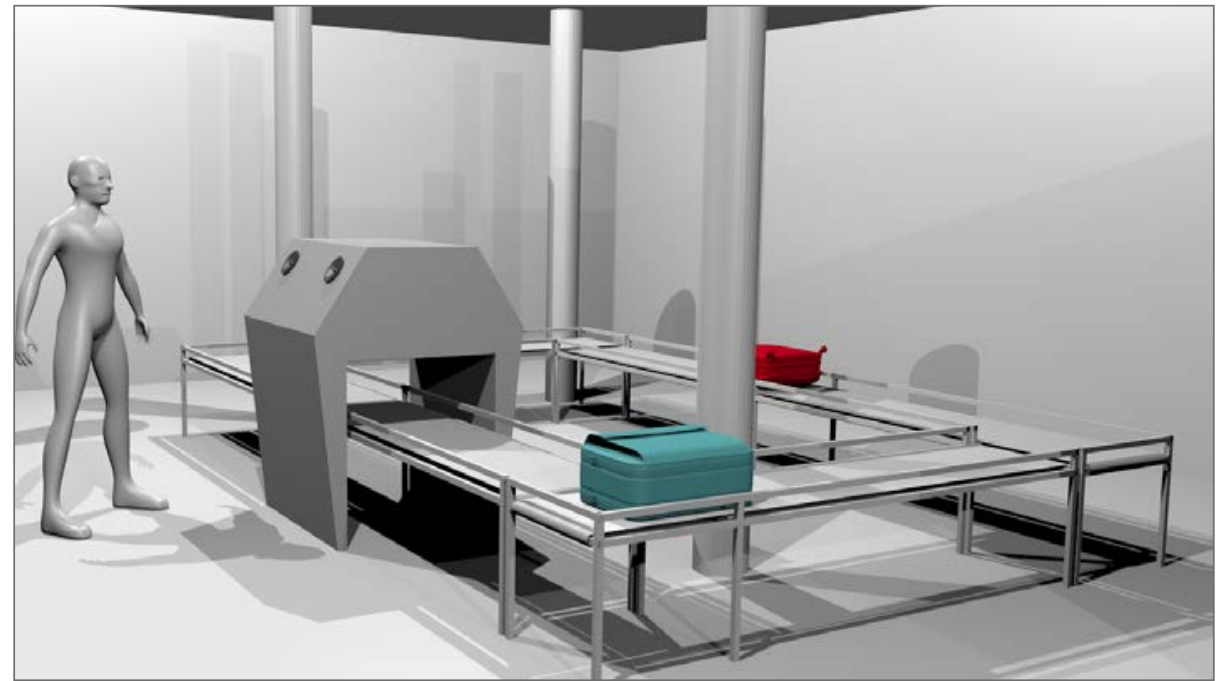

Fig. 7. Detalle de la última pieza.

\subsection{DESCRIPCIÓN TÉCNICA}

Para que la ejecución electrónica de la pieza número tres pueda realizarse, se necesita un micro controlador arduino, un sensor de color TCS3200, un shield de reproducción de mp3 para arduino, dos altavoces, cuatro motores DC reductores de $12 \mathrm{~V}$, fuente de alimentación externa y cables.

El micro controlador contiene un código compuesto por un algoritmo que es capaz de convertir la luz en frecuencia y filtrar los datos RGB para así obtener distintos valores e identificar un sin fin de colores. En base a cada color de las maletas se ha asociado un audio en mp3 y por medio de una serie de condicionales, los audios se activan sólo si el sensor detecta ese color específico. Entonces, al avanzar las maletas por la cinta, se identificará su color, los motores se detendrán y se pondrá en marcha la historia. Cuando ésta finaliza, los motores volverán a funcionar hasta que el sensor nuevamente detecte el color de una maleta, para así repetir la operación. 


\section{CONCLUSIONES}

La trascendencia de la historia oral como campo de estudio, se manifiesta en que cada testimonio oral es capaz de crear un contacto directo e individual con cada persona o grupo social que busca mantener vigente la memoria, rememorando su pasado, para así aportar una dimensión humana a la historia moderna positivista y crear nuevas formas en la producción de conocimiento, teniendo así, la capacidad de transformar las relaciones entre personas y su entorno.

Se desarrollaba a la par de la historia fines de siglo XIX, otra manera de acercarse a la historia a partir de nuevas fuentes que comienzan a dar voz a determinados actores no tomados en cuenta hasta ese momento. Se trata de nuevas comunidades que se revelan ante los grandes cambios que las marginan cada vez más y que les niegan las posibilidades de sobrevivencia (Iglesias Lesaga 2011), entregando voz a aquellos que por mucho tiempo no la tuvieron, permitiendo de esta manera democratizar los anales históricos.

En lo directamente concerniente al proyecto, para elaborar el conjunto de relatos se empleó una ésta metodología basada en entrevistas semiestructuradas y en la presentación de imágenes con el fin de revelar las emociones personales y obtener opiniones subjetivas en torno a cada imagen. En este sentido, se lograron muy buenos resultados en cuanto a la obtención de testimonios orales y a la foto elicitación, ya que por medio del uso de estas tecnologías blandas se pudo lograr el objetivo de generar dinámicas de trabajo con diversas comunidades y plasmar sus experiencias en una instalación sonora. La aplicación de estos métodos, entonces, sirvió para la obtención de un registro de audio de sus experiencias, transformándose así, en el eje central del proyecto, que interactuará con el usuario, vinculándolo con la historia oral y transmitiéndola activamente.

El testimonio oral obtenido proporciona un fragmento genuino directamente del protagonista de la historia, sin el filtro de la autoridad historiográfica de turno, al tiempo en que, al igual que el objetivo de esta propuesta artística, la historia oral obtenida registra, difunde y genera apreciación critica acerca de grupos sociales que no han recibido la atención que con urgencia requieren para la historia contemporánea. 


\section{Referencias}

Aja Fernández, Eliseo \& Joaquín Arango Vila-Belda, eds. 2006. Veinte años de inmigración en España: Perspectivas jurídica y sociológica (1985-2004). Barcelona : Fundació CIDOB

Baer Mieses, Alejandro. 2005. El testimonio audiovisual: Imagen y memoria del Holocausto. Madrid: Centro de Investigaciones Sociológicas

Barthes, Roland. (1980) 1990. La cámara lucida: Nota sobre la fotografía. Traducción de Joaquim Sala-Sanahuja. Barcelona: Paidos

- (1982) 1995. Lo obvio y lo obtuso: Imágenes, gestos, voces. Traducción C. Fernández Medrano. Barcelona: Paidos

Bermúdez Briñez, Nilda \& Marisol Rodríguez Arrieta. 2009. "Fuente oral en la reconstrucción de la memoria histórica: Aporte al documental Memorias del Zulia Petrolero". Revista de Ciencias Sociales 15(2):317-28. http://www.scielo.org.ve/scielo.php?script=sci_arttext\&pi$\mathrm{d}=$ S1315-95182009000200011\&lng=es\&tIng=es

Delgado Sahagún, Carolina. 2006. "Análisis del testimonio como fuente oral: género y memoria". En Viejas y nuevas alianzas entre América latina y España / XII Encuentro de Latino Americanistas españoles, Santander, 21 al 23 de septiembre, 1137-45. Santander: Consejo Español de Estudios Iberoamericanos

Harper, Douglas. 2002. "Talking about pictures: A case for photoelicitation". Visual Studies 17: $13-26$

Iglesias Lesaga, Esther. 2011. Reflexiones en torno a la importancia metodológica de la oralidad en la historia económica. Relaciones (Zamora) 32(128):289-314. http://www.scielo.org. $\mathrm{mx} /$ scielo.php?script=sci_arttext\&pid=S0185-39292011000400010\&lng=es\&tlng=es

Mariezkurrena Iturmendi, David. 2008. "La historia oral como método de investigación histórica". Gerónimo de Uztariz 23-24: 227-33 https://dialnet.unirioja.es/servlet/articulo?codigo $=3264024$

Mas Victori, Francesc. 2001. Rompiendo fronteras, una visión positiva de la inmigración. BarceIona: Intermón

Meyer, Eugenia \& Alicia Olivera de Bonfil. 1971. "La historia oral: Origen, metodología, desarrollo y perspectivas". Historia Mexicana 21(2): 372-87

Sanz Ramón, Fina. 2008. La fotobiografía: Imágenes e historias del pasado para vivir con plenitud el presente. Barcelona: Kairos

Schwarzstein, Dora. 1998. Una introducción al uso de la historia oral en el aula. Buenos Aires: Fondo de Cultura Económica

Shoah Fundation-The Institute for Visual History and Education (University of Southern California). 2016. "About the visual history archive". https://sfi.usc.edu/vha/about

Toop, David. 2013. Resonancia siniestra: El oyente como médium. Traducción Valeria Meiller. Buenos Aires: Caja Negra 